\title{
No link between season of birth and subsequent development of Graves' disease or toxic nodular goitre. A nationwide Danish register-based study
}

\author{
Suvanjaa Sivalingam ', Marianne Thvilum² ${ }^{2}$, Thomas Heiberg Brix ${ }^{2}$, Laszlo Hegedüs ${ }^{2,3}$ and Frans Brandtt ${ }^{1,4}$ \\ ${ }^{1}$ Department of Internal Medicine, Hospital of Southern Jutland, Sønderborg, Denmark \\ ${ }^{2}$ Department of Endocrinology and Metabolism, Odense University Hospital, Odense C, Denmark \\ ${ }^{3}$ Department of Clinical Research, University of Southern Denmark, Odense M, Denmark \\ ${ }^{4}$ Department of Regional Health Research, University of Southern Denmark, Odense M, Denmark
}

Correspondence should be addressed to F Brandt: frans.brandt.kristensen@rsyd.dk

\begin{abstract}
Background: Season of birth, an exogenous indicator of early life environment, has been linked with a higher risk of adverse health outcomes such as autoimmune thyroiditis, multiple sclerosis and schizophrenia later in life. Whether the development and cause of hyperthyroidism is influenced by season of birth is unclarified. We aimed, at a nationwide level, to investigate whether season of birth influences the risk of hyperthyroidism due to Graves' disease (GD) and/or toxic nodular goitre (TNG). Method: Register-based nationwide cohort study. By record-linkage between Danish health registers, 36,087 and 20,537 patients with GD and TNG, respectively, were identified. Each case was matched with four controls without thyroid disease, according to age and sex. Differences in month of birth across the year were evaluated by the Walter-Elwood test. Hazard ratios, for the risk of GD and TNG in individuals born in a certain month or season of the year, were calculated using Cox regression models. Results: Neither for GD nor for TNG could we demonstrate a significant difference in birth rate across months or seasons of the year (Walter-Elwood's test; $X^{2}=5.92$ and $X^{2}=1.27, P=0.052$ and $P=0.53$, respectively).

Conclusion: Irrespective of its cause, our findings do not support the hypothesis that season of birth is significantly related to the development of hyperthyroidism.
\end{abstract}

\author{
Key Words \\ - hyperthyroidism \\ - Graves' disease \\ - toxic nodular goitre \\ - birth month \\ register study
}

\section{Introduction}

Hyperthyroidism is a common condition with a lifetime risk of $2-10 \%(1,2)$. Graves' disease (GD) and toxic nodular goitre (TNG) are the most frequent causes of hyperthyroidism (2). GD is an organ specific autoimmune disease, which causes hyperthyroidism due to the presence of autoantibodies, which stimulate thyroid follicular cells by binding to the TSH receptor (1). In TNG, hyperthyroidism is the result of autonomous thyroid nodules, which produce thyroid hormones independent of TSH level (3). Irrespective of its cause, hyperthyroidism is a multifactorial condition, which develops as a result of a complicated and currently not fully understood interplay between genetic and environmental factors $(4,5,6,7)$. Iodine intake, alcohol and smoking habits are some of the environmental factors influencing the prevalence of hyperthyroidism $(5,8,9,10)$.

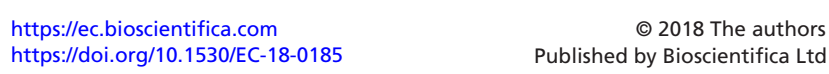


For several years, bacterial and/or viral infections have been suggested as biologically plausible environmental triggers in a number of autoimmune diseases, including GD $(11,12)$. Infections have been suggested to induce thyroid immunity by various mechanisms such as mimicking self-antigens, superantigen T-cell activation and inducing expression of human leucocyte antigens (13). In line with that, we have previously suggested that infection with Yersinia enterocolitica may increase the risk of GD (13). As the exposure to infections often follows a seasonal pattern, the observations of seasonal variations in month of birth among patients with autoimmune hypothyroidism (14), diabetes type 1 (15), multiple sclerosis and schizophrenia $(16,17)$ compared to the background population, further supports this hypothesis.

To our knowledge, the impact of month of birth for the development of GD has only received little attention (18, 19). Due to low power, the findings have been inconclusive. In contrast to GD, it has never been investigated whether TNG is influenced by seasonality in month of birth. However, seasonality in the time of diagnosis has been observed in patients with hyperthyroidism overall, and generally been attributed to variations in iodine intake and/or climatic factors (20).

In a register-based nationwide cohort study, we evaluated whether season of birth influences the risk of hyperthyroidism due to either GD or TNG.

\section{Materials and methods}

\section{Data sources}

Information regarding date of birth and death, vital status and demographics in the study population was obtained from The Danish Civil Registration System and The Danish Demographic Database (DDB) (21).

Information regarding thyroid status was obtained from The Danish National Patient Registry (DNPR) or The Danish National Prescription Registry (DNPrR) (21). DNPR covers, on an individual level, information on all hospital admissions since 1977 as well as outpatient visits since 1995. Diagnoses are coded according to The International Classification of Diseases (ICD) (21). In DNPrR all information on drug prescriptions dispensed from Danish pharmacies has been registered according to the Anatomical Therapeutic Chemical (ATC) classification system since 1995. The register holds information on date of dispensing, ATC code, strength and quantity (defined daily doses) (21).

\section{Hyperthyroidism}

A subject was classified as a case if he/she had an ICD-10 code for hyperthyroidism in DNPR in the period from January 1st 1995 through 31st of December 2012. GD was defined by the ICD-10 code E05.0 and TNG by the ICD-10 codes E05.1 or E05.2. Only individuals older than 18 years at diagnosis were included. Furthermore, in order only to include incident cases, the first 6 months of 1995 were used as a washout period.

In total, 56,624 subjects with a diagnosis of hyperthyroidism, of whom 36,087 had GD and 20,537 had TNG, were included in our study (Fig. 1).

A control was eligible for inclusion if he or she (1) did not have a diagnosis of hyperthyroidism at the time of the diagnosis in the corresponding case and (2) had no registration of ever receiving antithyroid medication $(\mathrm{ATC}=\mathrm{H03B})$ in DNPrR.

Following the principles of density sampling, each case was age and sex matched with four control individuals from the background population (22).

\section{Data analysis}

Statistical analyses were conducted using STATA version 13.0 (2013; Stata Corporation).

The association between GD or TNG and the risk of being born during a certain month of the year was evaluated by Cox regression. Age was chosen as the underlying time variable. To estimate differences in with-in year fluctuations across a 12-month period, the Walter-Elwood test for seasonality was used.

Likelihood ratio test (LR test) was used to test the significance of the Cox regression. The seasons were defined as winter (December, January and February), spring (March, April and May), summer (June, July and August) and autumn (September, October and November). December and winter was used as the reference for month and season, respectively. The exposure was month or season of birth and the outcome was either GD or TNG.

Significant differences were defined as a $P$ value below 0.05, using two-tailed tests.

\section{Results}

Selection and characteristics of the study population

The ascertainment of the study population is visualised in the flowchart (Fig. 1). The mean age at diagnosis of GD and TNG was 55.7 and 64.0 years, respectively. As expected, the majority of GD cases (81.3\%) as well as TNG cases $(83.8 \%)$ were women (Table 1$)$.

This work is licensed under a Creative Commons Attribution-NonCommercial-NoDerivatives 4.0 International License. 


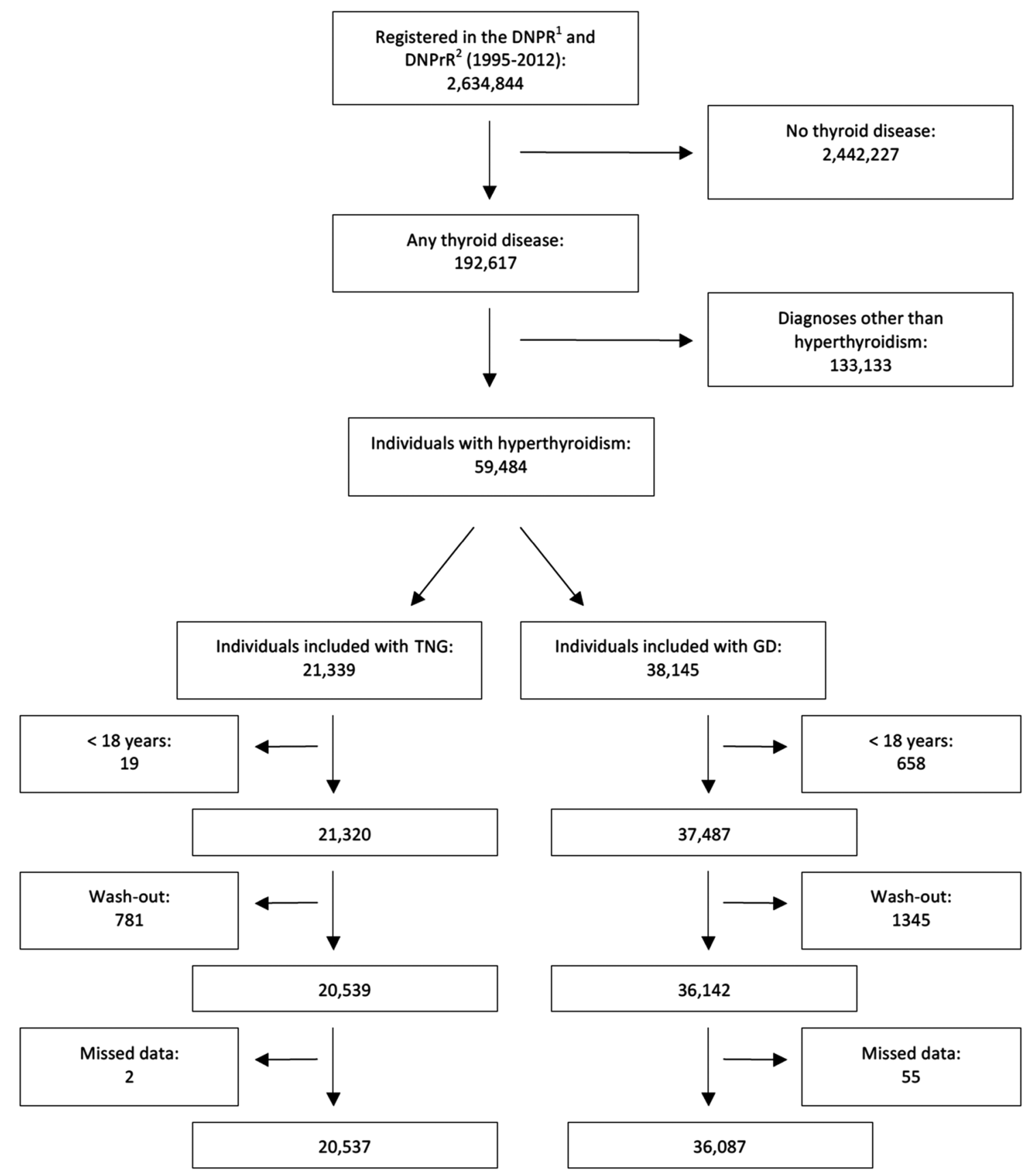

${ }^{1}$ The Danish National Patient Registry

${ }^{2}$ The Danish National Prescription Registry.

Figure 1

Flowchart showing the selection of cases with Graves' disease (GD) and toxic nodular goitre (TNG).

Impact of month or season of birth for development of GD or TNG

The overall results are summarised in Fig. 2 and Table 2. Neither for GD nor for TNG could we demonstrate a significant difference in birth rate across months or seasons of the year (Walter-Elwood test; $X^{2}=5.92$ and $\mathrm{X}^{2}=1.27, P=0.052$ and $P=0.53$, respectively). Changing the reference month from December to any other month had no significant influence on the results of the Cox regression analyses (data not shown). Stratification for being born before 1960 or in 1960 or later showed https://ec.bioscientifica.com https://doi.org/10.1530/EC-18-0185 
Table 1 Demographic characteristics of the study population.

\begin{tabular}{|c|c|c|}
\hline Population & $\mathbf{G D}^{1}$ & Controls \\
\hline Number $(n)$ & 36,087 & 144,348 \\
\hline Females (\%) & $29,321(81.3)$ & 117,355 (81.3) \\
\hline Males (\%) & 6766 (18.7) & $26,271(18.2)$ \\
\hline Population & $\mathrm{TNG}^{2}$ & Controls \\
\hline Number $(n)$ & 20,537 & 82,148 \\
\hline Females (\%) & $17,202(83.8)$ & $68,002(83.8)$ \\
\hline Males (\%) & 3335 (16.2) & $13,307(16.2)$ \\
\hline
\end{tabular}

${ }^{1}$ Graves' disease. ${ }^{2}$ Toxic nodular goitre.

a significant difference in the Walter-Elwood test in individuals born before 1960 and diagnosed with GD $(P=0.008)$ but not for those with TNG $(P=0.785)$. For individuals born 1960 or later, there was no significant difference in the Walter-Elwood test, whether in GD $(P=0.540)$ or in TNG $(P=0.235)$. The LR test for the Cox regression analyses was not significant. Stratification for sex showed significant difference in the Walter-Elwood test in men, both for GD $(P=0.001)$ and for TNG $(P=0.024)$. This was neither seen in women with GD $(P=0.14)$ nor with TNG $(P=0.31)$. Also in these analyses the LR-test was insignificant $(P=0.72)$.

\section{Discussion}

Utilising population-based nationwide Danish registers, and based on more than 56,000 patients with hyperthyroidism, we found no statistically significant association between the month or season of birth and the risk of developing GD or TNG later in life. The overall interpretation was not significantly influenced by stratification for gender or being born before or after 1960 . In other words, irrespective of its cause, our findings do not support the hypothesis that season of birth is related to the development of hyperthyroidism. In this way another negative finding in the aetiology of hyperthyroidism has been added to that of our previous findings of lack of influence of a number of birth characteristics, such as birth weight, birth length, birth order and prematurity (23).

To our knowledge, the association between month or season of birth and risk of GD has been evaluated in two previous studies, while this has never been studied in TNG. Hamilton et al. (19) investigated the association between month or season of birth and subsequent risk of autoimmune thyroid disease. Based on nearly 3800 GD patients from three different study populations, the authors concluded that no consistent month of birth
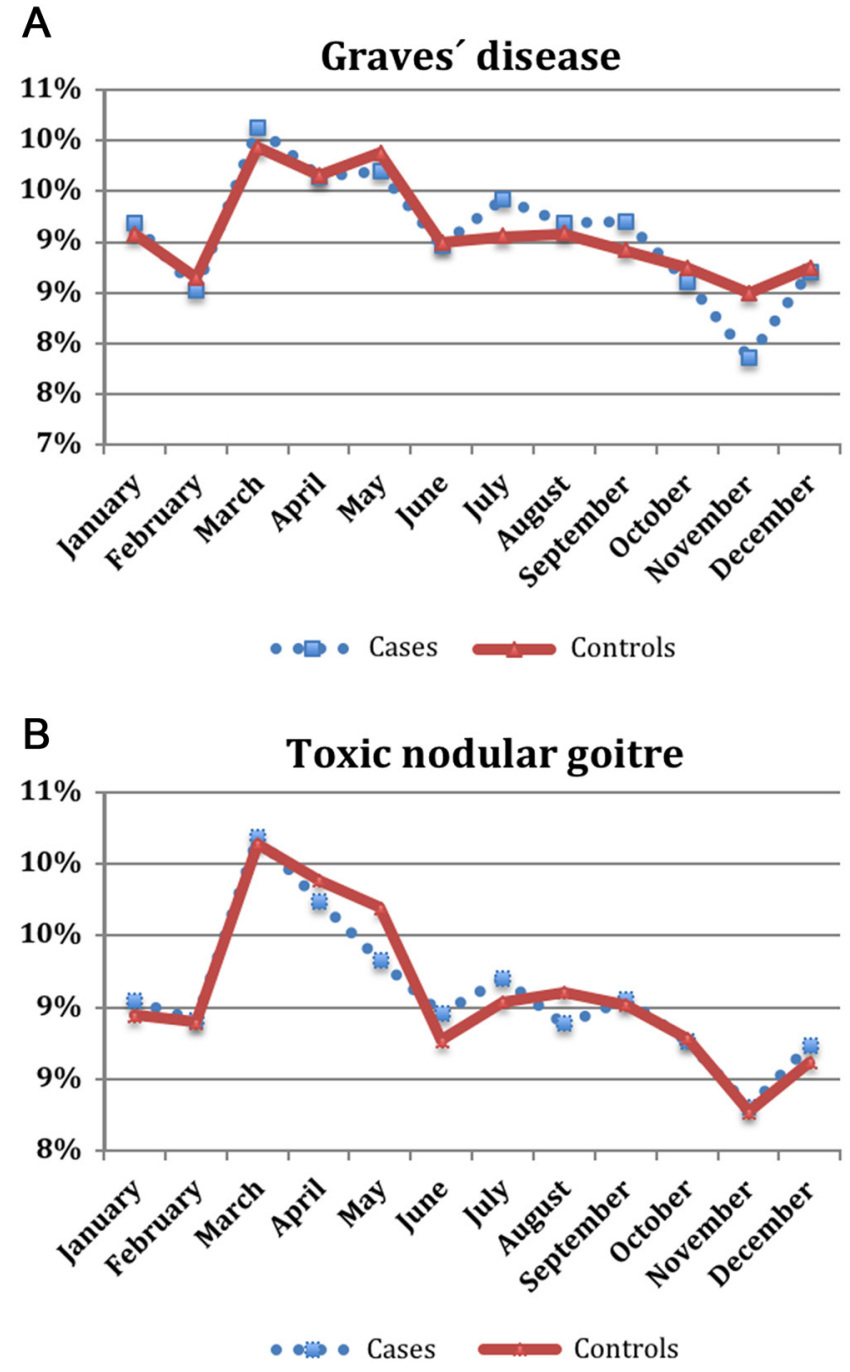

Figure 2

Distribution of month of birth among cases with Graves' disease (A) and toxic nodular goitre (B), respectively, and controls. Walter-Elwood test, $P$ value $=0.052$ and 0.53 for Graves' disease and toxic nodular goitre, respectively.

effects were detected in GD. In contrast, a study from Greece showed a peak in developing GD for males born during the winter and for females born in the spring and the autumn (18). However, the latter study was quite small as it was based on only 359 GD patients ascertained from a single centre. In addition, the distribution of birth months of the cases was compared with the national and not the regional distribution which could influence their findings. Recently, based on the same methodology and design as the present study, we found a significantly increased risk of developing autoimmune hypothyroidism when born in the summer season, especially June (14). Interestingly, in line with our results, Hamilton et al. found that variation in month of birth was related to a

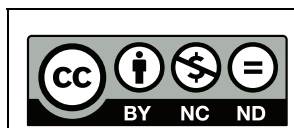
This work is licensed under a Creative Commons
Attribution-NonCommercial-NoDerivatives 4.0 International License. 
Table 2 Cox regression of the association between month and season of birth and risk of Graves' disease and toxic nodular goitre, respectively, as compared to controls.

\begin{tabular}{|c|c|c|}
\hline \multirow[b]{2}{*}{ Month/season } & \multicolumn{2}{|c|}{ Hazard ratio, $95 \% \mathrm{Cl}^{5}$} \\
\hline & $\mathrm{GD}^{3}$ & $\mathrm{TNG}^{4}$ \\
\hline January $^{1}$ & $1.00(0.95-1.05)$ & $0.90(0.91-1.05)$ \\
\hline February ${ }^{1}$ & $0.99(0.94-1.05)$ & $0.99(0.92-1.06)$ \\
\hline March $^{1}$ & $1.02(0.97-1.08)$ & $1.01(0.95-1.08)$ \\
\hline April $^{1}$ & $1.02(0.47-1.07)$ & $1.00(0.93-1.06)$ \\
\hline May & $1.00(0.95-1.05)$ & $1.00(0.93-1.07)$ \\
\hline June $^{1}$ & $1.03(0.97-1.07)$ & $1.05(0.98-1.12)$ \\
\hline July ${ }^{1}$ & $1.04(0.99-1.09)$ & $1.02(0.90-1.1)$ \\
\hline August $^{1}$ & $1.00(0.96-1.06)$ & $0.99(0.93-1.06)$ \\
\hline September ${ }^{1}$ & $1.04(0.99-1.04)$ & $1.01(0.95-1.08)$ \\
\hline October $^{1}$ & $0.99(0.94-1.04)$ & $1.02(0.95-1.09)$ \\
\hline November $^{1}$ & $0.95(0.90-1.00)$ & $1.04(0.97-1.11)$ \\
\hline Spring $^{2}$ & $-0.002(-0.031-0.026)$ & $1.01(0.98-1.05)$ \\
\hline Summer ${ }^{2}$ & $0.004(-0.02-0.038)$ & $1.03(0.99-1.08)$ \\
\hline Autumn ${ }^{2}$ & $-0.017(-0.047-0.012)$ & $1.03(0.99-1.08)$ \\
\hline
\end{tabular}

${ }^{1}$ Reference month December. ${ }^{2}$ Reference season winter. ${ }^{3} \mathrm{Graves}$ ' disease. ${ }^{4}$ Toxic nodular goitre. ${ }^{5}$ Confidence interval.

subsequent diagnosis of autoimmune hypothyroidism but not to GD (19). Neither we nor others have obvious explanations for the discrepancy in seasonal variation in birth between these two phenotypes, and the databases used here do not contain information on genetics or the huge number of environmental variables which, at a multitude of levels interact and could give insight into this conundrum.

The fact that we found no significant association with either GD or TNG does not violate the hypothesis that season of birth influences other autoimmune diseases. Studies indicate that Epstein-Barr virus infection during the winter is associated with multiple sclerosis, and rotavirus infections during the winter stimulate the development of diabetes type I (17). In contrast, Crohn's disease does not have significant seasonal variation (24). A plausible explanation for these differences could be disease-specific interactions between susceptibility genes and environmental factors (25).

All autoimmune diseases are probably caused by a combination of innate and adaptive immune regulatory abnormalities, but most probably not in the same way. Autoimmune conditions are more or less disease specific with different immune responses.

A clear strength of the present study is the inclusion of a large cohort from the entire Danish population selected from robust and validated registers. Other advantages are the relatively long follow-up period, clear case definitions and very few individuals lost to follow-up due to the register-based setting.
Despite this, our results should be interpreted in the light of possible limitations. The data were gathered from various registers, which are all based on the civil registration (CPR) numbers. These identifiers were not restricted to Danish born, but only to Danish-resident individuals. Accordingly, immigrants have been included without taking environmental and genetic confounding factors into consideration. However, based on information from Statistics Denmark (www.dst.dk), around 90\% of the Danish population is Caucasian. Therefore, this limitation is unlikely to have had major impact on our results. Also the lack of clinical and biochemical data, including determination of TSH receptor antibodies or morphologic evaluation by thyroid scintigraphy or ultrasound, allowing even better subclassification, are limitations but no such data are available in the registers. When this is said, DNPR has been validated with respect to accuracy of hyperthyroidism and misclassification occurs in less than $2 \%$ of cases (26). Since autoimmune diseases are associated, another limitation could be the lack of considering whether patients with GD had additional autoimmune diseases with month of birth variation (27). Finally, lack of information on other environmental triggers such as smoking and alcohol intake, long known to affect aetiology of thyroid diseases, might have influenced the results because the consumption varies considerably among individuals $(9,10,28)$.

In conclusion, the present study, incorporating the entire Danish population, disclosed no significant association between month or season of birth and the subsequent diagnosis of GD or TNG.

\section{Declaration of interest}

The authors declare that there is no conflict of interest that could be perceived as prejudicing the impartiality of the research reported.

\section{Funding}

No separate funding of this work. Frans Brandt has received funding from the Region of Southern Denmark. Laszlo Hegedüs has received funding from the Novo Nordisk Foundation.

\section{Author contribution statement}

Idea: All authors. Writing: All authors. Data collection and processing: Frans Brandt and Marianne Thvilum.

\section{Ethical considerations}

Due to the register-based design, utilising historical and anonymised register data, there has been no direct patient involvement in the study. Therefore, according to Danish law, no patient consent need be obtained. However, the study, also according to Danish law, has been approved by the Danish Data Protection Agency (project number: 704047).

\section{This work is licensed under a Creative Commons} Attribution-NonCommercial-NoDerivatives 4.0 International License. 


\section{References}

1 Smith TJ \& Hegedüs L. Graves' disease. New England Journal of Medicine 2016375 1552-1565. (https://doi.org/10.1056/ NEJMra1510030)

2 De Leo S, Lee SY \& Braverman LE. Hyperthyroidism. Lancet 2016388 906-918. (https://doi.org/10.1016/S0140-6736(16)00278-6)

3 Sharma M, Aronow WS, Patel L, Gandhi K \& Desai H. Hyperthyroidism. Medical Science Monitor 201117 85-91.

4 Brix TH \& Hegedüs L. Twin studies as a model for exploring the aetiology of autoimmune thyroid disease. Clinical Endocrinology 2012 76 457-464. (https://doi.org/10.1111/j.1365-2265.2011.04318.x)

5 Laurberg P, Pedersen KM, Vestergaard H \& Sigurdsson G. High incidence of multinodular toxic goitre in the elderly population in a low iodine intake area vs. high incidence of Graves' disease in the young in a high iodine intake area: comparative surveys of thyrotoxicosis epidemiology in East-Jutland Denmark and Iceland. Journal of Internal Medicine 1991229 415-420. (https://doi. org/10.1111/j.1365-2796.1991.tb00368.x)

6 Brix TH, Kyvik KO, Christensen K \& Hegedüs L. Evidence for a major role of heredity in Graves' disease: a population-based study of two Danish twin cohorts. Journal of Clinical Endocrinology and Metabolism 200186 930-934.

7 Brix TH, Kyvik KO \& Hegedüs L. Major role of genes in the etiology of simple goiter in females: a population-based twin study. Journal of Clinical Endocrinology and Metabolism 199984 3071-3075.

8 Carlé A, Bülow Pedersen I, Knudsen N, Perrild H, Ovesen L, Rasmussen LB, Jørgensen T \& Laurberg P. Graves' hyperthyroidism and moderate alcohol consumption: evidence for disease prevention. Clinical Endocrinology 201379 111-119.

9 Hegedüs L, Brix TH \& Vestergaard P. Relationship between cigarette smoking and Graves' ophthalmopathy. Journal of Endocrinological Investigation 200427 265-271.

10 Brix TH, Hansen PS, Kyvik KO \& Hegedüs L. Cigarette smoking and risk of clinically overt thyroid disease: a population-based twin casecontrol study. Archives of Internal Medicine 2000160 661-666.

11 Ferrari SM, Fallahi P, Antonelli A \& Benvenga S. Environmental issues in thyroid diseases. Frontiers in Endocrinology 2017850.

12 Ajjan R \& Weetman A. The pathogenesis of Hashimoto's thyroiditis: further developments in our understanding. Hormone and Metabolic Research 201547 702-710. (https://doi.org/10.1055/s-0035-1548832)

13 Brix TH, Hansen PS, Hegedüs L \& Wenzel BE. Too early to dismiss Yersinia enterocolitica infection in the aetiology of Graves' disease: evidence from a twin case-control study. Clinical Endocrinology 2008 69 491-496. (https://doi.org/10.1111/j.1365-2265.2008.03227.x)

14 Thvilum M, Brandt F, Brix TH \& Hegedüs L. Month of birth is associated with the subsequent diagnosis of autoimmune hypothyroidism. A nationwide Danish register-based study. Clinical Endocrinology 201787 832-837. (https://doi.org/10.1111/cen.13425)

15 Vaiserman AM, Carstensen B, Voitenko VP, Tronko MD, Kravchenko VI, Khalangot MD \& Mechova LV. Seasonality of birth in children and young adults ( $0-29$ years) with type 1 diabetes in Ukraine. Diabetologia 200750 32-35. (https://doi.org/10.1007/ s00125-006-0456-4)

16 Cheng C, Loh E-W, Lin C-H, Chan C-H \& Lan T-H. Birth seasonality in schizophrenia: effects of gender and income status. Psychiatry and
Clinical Neurosciences 201367 426-433. (https://doi.org/10.1111/ pcn.12076)

17 Watad A, Azrielant S, Bragazzi NL, Sharif K, David P, Katz I, Aljadeff G, Quaresma M, Tanay G, Adawi M, et al. Seasonality and autoimmune diseases: the contribution of the four seasons to the mosaic of autoimmunity. Journal of Autoimmunity 201782 13-30. (https://doi.org/10.1016/j.jaut.2017.06.001)

18 Krassas GE, Tziomalos K, Pontikides N, Lewy H \& Laron Z. Seasonality of month of birth of patients with Graves' and Hashimoto's diseases differ from that in the general population. European Journal of Endocrinology 2007 156 631-636. (https://doi. org/10.1530/EJE-07-0015)

19 Hamilton A, Newby PR, Carr-Smith JD, Disanto G, Allahabadia A, Armitage M, Brix TH, Chatterjee K, Connell JM, Hegedüs L, et al. Impact of month of birth on the development of autoimmune thyroid disease in the United Kingdom and Europe. Journal of Clinical Endocrinology and Metabolism 201499 1459-1465. (https://doi. org/10.1210/jc.2014-1270)

20 Buchinger W, Semlitsch G, Pongratz R, Harwalik B \& Rainer F. Seasonal variations in the diagnosis of hyperthyroidism. Acta Medica Austriaca 200027 51-53. (https://doi.org/10.1046/j.15632571.2000.00206.x)

21 Thygesen LC, Daasnes C, Thaulow I \& Bronnum-Hansen H. Introduction to Danish (nationwide) registers on health and social issues: structure, access, legislation, and archiving. Scandinavian Journal of Public Health 201139 12-16. (https://doi. org/10.1177/1403494811399956)

22 Lubin JH \& Gail MH. Biased selection of controls for case-control analyses of cohort studies. Biometrics 198440 63-75. (https://doi. org/10.2307/2530744)

23 Brix TH, Kyvik KO \& Hegedüs L. Low birth weight is not associated with clinically overt thyroid disease: a population based twin casecontrol study. Clinical Endocrinology 200053 171-176. (https://doi. org/10.1046/j.1365-2265.2000.01025.x)

24 Disanto G, Chaplin G, Morahan JM, Giovannoni G, Hyppönen E, Ebers GC \& Ramagopalan SV. Month of birth, vitamin D and risk of immune- mediated disease: a case control study. BMC Medicine 2012 10 69. (https://doi.org/10.1186/1741-7015-10-69)

25 Dempfle A, Scherag A, Hein R, Beckmann L, Chang-Claude J \& Schäfer H. Gene-environment interactions for complex traits: definitions, methodological requirements and challenges. European Journal of Human Genetics 200816 1164-1172. (https://doi. org/10.1038/ejhg.2008.106)

26 Thomsen AF, Kvist TK, Andersen PK \& Kessing LV. Increased risk of developing affective disorder in patients with hypothyroidism: a register-based study. Thyroid 200515 700-707. (https://doi. org/10.1089/thy.2005.15.700)

27 Boelaert K, Newby PR, Simmonds MJ, Holder RL, Carr-Smith JD, Heward JM, Manji N, Allahabadia A, Armitage M, Chatterjee KV, et al. Prevalence and relative risk of other autoimmune diseases in subjects with autoimmune thyroid disease. American Journal of Medicine 2010 123 1-9. (https://doi.org/10.1016/j.amjmed.2010.10.001)

28 Hegedüs L, Rasmussen N, Ravn V, Kastrup J, Krogsgaard K \& Aldershvile J. Independent effects of liver disease and chronic alcoholism on thyroid function and size: the possibility of a toxic effect of alcohol on the thyroid gland. Metabolism 198837 229-233.
Received in final form 31 July 2018

Accepted 23 August 2018

Accepted Preprint published online 23 August 2018 https://ec.bioscientifica.com https://doi.org/10.1530/EC-18-0185 (c) 2018 The authors Published by Bioscientifica Ltd
This work is licensed under a Creative Commons Attribution-NonCommercial-NoDerivatives 4.0 International License. 